\title{
Is a family history of coronary heart disease an independent coronary risk factor?
}

\author{
RONAN M CONROY, * RISTEARD MULCAHY „ NOEL HICKEY,† LESLIE DALY† \\ From the ${ }^{\star}$ Cardiac Department and Department of Preventive Cardiology, and the $\dagger$ Department of Community \\ Medicine and Epidemiology, St Vincent's Hospital and University College, Dublin, Ireland
}

SUMMARY The importance of a positive family history as a primary risk factor for coronary heart disease was examined in a case history study. Of 792 consecutive male patients aged under 60 years who survived a first episode of unstable angina or myocardial infarction, 326 had a negative family history, 298 had a positive history, and in 168 a family history could not be established with certainty. There was no significant difference in the distribution of the three primary coronary risk factois - cigarette smoking, hypertension, and hypercholesterolaemia-between those with and those without a positive family history. The 133 subjects with a positive family history of premature coronary heart disease (occurrence in near relatives under 60 years) were significantly younger than those with a negative family history.

It is concluded that there is little evidence to confirm a positive family history as an important independent risk factor for coronary heart disease, although there may be familial aggregation of subjects with a high susceptibility to the effects of the three primary risk factors, cigarette smoking, hypertension, and hyperlipidaemia.

Although a positive family history is widely accepted as an independent risk factor for coronary heart disease, there is little published evidence to support this view. It has been suggested that the aggregation of coronary disease in families can be attributed to the high prevalance of the condition in Western society and to family aggregation of coronary heart disease risk factors, including hyperlipidaemia, hypertension, obesity, smoking, and diabetes.

There are three ways in which a positive family history might be related to the development of coronary heart disease: $(a)$ as an index of the inheritance of risk factors; $(b)$ as a truly independent risk factor; and (c) as a vulnerability factor potentiating the action of risk factors.

Studies of familial aggregation of coronary heart disease are usually either case-control studies of its prevalence in the relatives of patients and of matched controls 1 or prospective studies at population level. ${ }^{2}$ An alternative approach is to examine the risk factor profiles of patients with established coronary heart

Requests for reprints to Mr Ronán M Conroy, Cardiac Department, St Vincent's Hospital, Elm Park, Dublin 4, Ireland.

Accepted for publication 7 December 1984 disease. If we take the occurrence of the first acute coronary event as marking a definable stage in the progress of the disease we may make specific predictions about the relation between family history and other risk factors in patients at this stage of disease progression.

If family history of coronary heart disease is simply an index of the inheritance of one or more risk factors, we would expect to find a different risk factor profile in patients with a positive history. If, on the other hand, a positive family history is an independent risk factor for coronary heart disease we would expect to find lower frequencies of other acknowledged risk factors among patients with a positive history than among those with a negative history. The third possibility is that family history acts as a potentiating factor to one or more risk factors-for example, by the genetic transmission of a tendency to narrow blood vessels. In this case, we would expect to see the same combination of risk factors in patients with and without a family history, but we would expect the former group to be younger at the time of their first acute episode.

The aim of this study was to examine the risk factor profiles of survivors of a first episode of unstable angina or myocardial infarction to determine whether 
they provided support for any of the models outlined above.

\section{Patients and methods}

Cases were drawn from the St Vincent's Hospital Heart Study. This is a long term follow up study of consecutive 28 day survivors of a first acute episode of coronary heart disease. Cohort 1 was recruited between 1965 and 1975 and cohort 2 between 1978 and 1983. The patients included in the present analysis were male and aged under 60 years and had survived a first episode of unstable angina or myocardial infarction by 28 days. Patients with unstable angina were included only if, in the presence of typical cardiac pain at rest, they had serial ST-T changes in the electrocardiogram with either no increase or a less than twofold increase in cardiac enzyme activities (creatine kinase, lactic dehydrogenase, and aspartate aminotransferase). Myocardial infarction was diagnosed on the basis of cardiac pain at rest with new $Q$ waves in the electrocardiogram or at least a twofold rise in cardiac enzyme activities or both.

Family history of coronary heart disease was defined as one or more of the patient's parents or siblings having an acute episode of coronary heart disease or having angina of effort. Additional information on family history was available for patients in cohort 1 allowing a comparison to be made between patients without a family history and those of whom at least one parent or sibling under the age of 60 had had an acute event or angina of effort. Two analyses were therefore performed, one comparing patients without a family history with those with a positive history, the other comparing patients without a family history with those with a family history of premature coronary heart disease. In several instances the family history could not be rated confidently because of early parental death, loss of centact with family members, or similar reasons. Such patients were excluded from the study. Table 1 shows distribution of family history of coronary heart disease for the two analyses.

Other risk factors were defined as follows: cigarette smoking was rated as 0 , for non-smokers; 1 , for ex- smokers, and 2, for current smokers. An ex-smoker was defined as not having smoked for three months or more before the admitting episode. The relation of weight to height was calculated using Quetelet's body mass index, which is the ratio between the patient's weight (in $\mathrm{kg}$ ) and his height squared (in $\mathrm{m}^{2}$ ). Total serum cholesterol concentration was assayed from a blood sample usually taken within 12 hours of the onset of an attack. Hypertension was diagnosed in patients fulfilling at least one of the following criteria: (a) a diastolic blood pressure $>90 \mathrm{~mm} \mathrm{Hg}$ during hospital stay; (b) a diastolic blood pressure consistently $>110 \mathrm{~mm} \mathrm{Hg}$ measured at the outpatient clinic; (c) treatment for hypertension before the admitting episode, or $(d)$ the presence of at least two of the following: a past history of hypertension, electrocardiographic evidence of left ventricular hypertrophy, or hypertensive retinopathy.

All the factors were examined individually for differences between family history groups and simultaneously by means of discriminant function analysis. A discriminant function produces the optimal combination of a number of measures for the purpose of discriminating between a number of subgroups.

\section{Results}

Risk factor data were available for 792 patients who fulfilled the entry criteria. These comprised 553 consecutive admissions between 1965 and 1975 inclusive (cohort 1) and 239 consecutive admissions between 1978 and 1982 inclusive (cohort 2). Table 1 shows the distribution of family history of coronary heart disease in the two cohorts. One hundred and sixty eight patients were unable to provide enough information for us to rate family history with certainty and were excluded from the analysis. Of the remaining 624, 326 (52\%) had a negative family history.

Table 2 shows the distribution of the individual risk factors between the two family history groups. In the first analysis, in which subjects with a positive history were compared with those without, levels of individual risk factors were similar in both groups, with the exception of serum cholesterol concentration; the

Table 1 Distribution of family history of coronary heart disease (CHD). Figures are numbers (\%) of subjects

\begin{tabular}{|c|c|c|c|}
\hline Coronary heart disease & Cohort 1 & Cohort 2 & Total \\
\hline $\begin{array}{l}\text { Negative history } \\
\text { Doubtful history }\end{array}$ & $\begin{array}{l}236(42.7) \dagger \\
135(24 \cdot 4)\end{array}$ & $\begin{array}{l}90(37.7) \\
33(13.8)\end{array}$ & $\begin{array}{l}326(41 \cdot 2)^{\star} \\
168(21 \cdot 2)\end{array}$ \\
\hline $\begin{array}{l}\text { History in parent or sibling: } \\
\text { Aged } \geqslant 60 \\
\text { Aged }<60 \\
\text { Any age } \\
\text { Total }\end{array}$ & $\begin{array}{l}49(8.9) \\
133(24 \cdot 0) \dagger \\
182(32.9) \\
553(100)\end{array}$ & $\begin{array}{l}\text { NA } \\
\text { NA } \\
116(48 \cdot 5) \\
239(100)\end{array}$ & ${ }_{792}^{298}(37 \cdot 6)^{\star}$ \\
\hline
\end{tabular}

NA, not applicable.

$\star$ Data compared in analysis 1 .

tData compared in analysis 2 . 
Table 2 Distribution of risk factors in relation to negative or positive family history

\begin{tabular}{|c|c|c|c|c|}
\hline & \multicolumn{2}{|c|}{ Analysis It } & \multicolumn{2}{|c|}{ Analysis $2 \ddagger$} \\
\hline & Negative & Positive & Negative & Positive \\
\hline $\begin{array}{l}\text { Number of cases } \\
\% \text { of current smokers } \\
\% \text { of patients with known hypertension } \\
\text { Mean cholesterol concentration }(\mathrm{mg} / 100 \mathrm{ml}) \\
\text { Mean age (years) } \\
\text { Mean body mass index }\end{array}$ & $\begin{array}{r}326 \\
71 \cdot 8 \\
17 \cdot 2 \\
244 \cdot 6 \\
50 \cdot 9 \\
24 \cdot 8\end{array}$ & $\begin{array}{r}298 \\
65 \cdot 1 \\
14 \cdot 1 \\
253 \cdot 4 \\
50 \cdot 2 \\
25 \cdot 2\end{array}$ & $\begin{array}{r}236 \\
75.4 \\
15 \cdot 7 \\
252 \cdot 1 \\
51 \cdot 2 \\
24.8\end{array}$ & $\begin{array}{c}133 \\
70 \cdot 7 \\
18 \cdot 1 \\
260 \cdot 5 \\
49 \cdot 5^{\star} \\
25 \cdot 0\end{array}$ \\
\hline
\end{tabular}

«Significant: $t=2 \cdot 29, \mathrm{df}=252, \mathrm{p}=0.023$ (separate variance estimate); no other differences significant. $\chi^{2}$ test (smoking, hypertension), and grouped $t$ test (cholesterol, age, body mass index) used.

tAll negative cases $v s$ all positive cases.

Negative cases $v s$ coronary heart disease in parent or sibling $<60$ years for cohort 1.

Conversion: traditional to SI units-cholesterol: $1 \mathrm{mg} / 100 \mathrm{ml} \approx 0.026 \mathrm{mmol} / 1$.

subjects without a family history had a cholesterol concentration $0.2 \mathrm{mmol} / 1(9 \mathrm{mg} / 100 \mathrm{ml})$ lower than those with a positive history. This difference was of borderline significance $(t=1 \cdot 76, p=0.079$, separate variance estimate used). In the second analysis, in which subjects with a family history of premature disease (in a near relative under 60 years) were compared with those with no family history, the distribution of risk factors was again similar in both groups, but the mean age of those with a positive history was 1.7 years lower than that of subjects with a negative history $(p=0.023)$. No difference in mean cholesterol concentration was found between the two groups.

Attempts to find a characteristic risk factor profile that distinguished subjects with a positive family history from those without, using discriminant function analysis, were unsuccessful. Using age, cholesterol concentration, body mass index, smoking status, and hypertension, stepwise functions were calculated. The optimal combination of these factors explained only $1.75 \%$ of variance between positive and negative family history groups. When subjects with a negative history were compared with those with a history of premature coronary heart disease, the percentage of variance explained rose to $2 \cdot 16 \%$, but the function was only able to classify subjects into the appropriate family history groups with $55 \%$ accuracy-that is, $5 \%$ better than chance expectancy.

In addition, we examined the risk factors of the subjects in whom a firm rating of family history could not be made. They did not differ significantly from other subjects in any of the factors studied.

\section{Discussion}

There is a well established aggregation of coronary risk factors and of cases of coronary heart disease in families. ${ }^{34}$ This may be attributed to the frequency of the condition in Western society, to a shared family environment, to a genetic susceptibility to the effects of individual risk factors, to a greater predispostion to individual risk factors, to a primary genetic predispo- sition to atherosclerosis, or to a combination of two or more of these factors. The concept of a genetic predisposition has occupied the minds of previous authors, but no agreement has been reached about the importance of family history as a primary risk factor.

Epstein, in earlier reviews, states that there is little support for the unqualified statement that "the family history is important" in predicting the risk of coronary heart disease in the individual. ${ }^{56} \mathrm{He}$ does imply, however, that the clustering of hyperlipidaemia and hypertension in families is not sufficient to account for the entire aggregation of cases of coronary heart disease within families. The clustering of known or unknown risk factors, including cigarette smoking, diabetes, and obesity, may possibly contribute further to family aggregation.

McKusick, in an earlier review, states that among the few twin studies of clinical coronary heart disease, the majority are consistent with the hypothesis of an important genetic factor. ${ }^{7} \mathrm{He}$ quotes studies of monozygotic twins living together and apart, which would support the influence of both environmental and genetic factors.

The Western Collaborative Study reported that a positive family history was independently predictive of coronary heart disease only in men aged less than 50 years. ${ }^{8}$ In the Paris Prospective Study of 7484 men it was found that a paternal, but not a maternal, history was independently predictive of coronary heart disease. ${ }^{9}$ In a study of 186 pairs of brothers in Framingham coronary heart disease in an older brother was predictive of both non-fatal and fatal myocardial infarction in the younger sibling, after controlling for cholesterol concentration, cigarette smoking, and hypertension. ${ }^{10}$

Ten Kate et al report a case control study of 145 male survivors of myocardial infarction matched with 145 apparently healthy male blood donors and compared with an equal number of first degree relatives of both groups. ${ }^{1}$ They conclude that family aggregation of coronary heart disease is not entirely explained by clustering of known risk factors. They state that such 
an aggregation could be caused by undefined genetic factors, by environmental factors, or by a combination of both.

In a recent study involving a nine year follow up of 4014 healthy men and women, Barrett-Connor and Khaw found that men under 60 years with a positive family history had higher mean blood pressure and plasma cholesterol concentrations than those with a negative history, while older men with a positive history had a higher incidence of diabetes. ${ }^{2}$ Young women with a positive family history were more likely to smoke cigarettes and older women to have taken exogenous oestrogens. They found that, in younger men only, a positive family history was independently predictive of death from cardiovascular and all causes but not from coronary heart disease. On the other hand, a prospective study of $\mathbf{4 0 5 0}$ men in Finland failed to show any association between family history of premature coronary heart disease (under age 50) and risk of either stroke or myocardial infarction ${ }^{11}$ when other risk factors were controlled for.

Our own results fail to elucidate the problem, but they do not support the hypothesis of a genetic influence as an independent risk factor. The nonsignificant but higher cholesterol concentrations in our patients with a positive family history do not exclude the possibility of a subgroup of patients with a genetic tendency to hyperlipidaemia, and the younger age of patients with a positive family history of premature disease is consistent with an inherited susceptibility to the action of coronary risk factors. Our results, however, like those of previous studies, serve mainly to emphasise the uncertainties that still exist about the importance of a family history and to point to the need for further research into this area. It is possible that a definitive answer may not be found to the question because of the difficulties inherent in studies of this type, in which a primary risk factor must be distinguished from a genetic tendency to acknowledged risk factors, an increased susceptibility in some families to the effect of such risk factors, and the shared environmental influences that exist within families. The situation may be compounded further by the probability that two or more of these factors may be operative and by the fact that the family history status may change with the development of new cases of coronary heart disease in family members.

Perhaps the only, and certainly the most important, conclusion that can be drawn from our study of a large group of patients and from previous studies is that a positive family history is not an independent primary risk factor of the same magnitude as hyperlipidaemia, hypertension, or smoking. This is supported by the results of migration studies and by our own study of risk factors in 757 male patients under 60 years with a first myocardial infarction. ${ }^{12}$ Only 14 of these patients were free of the three primary risk factors (never smoked cigarettes, had normal blood pressure, and had a serum cholesterol concentration $<6.2 \mathrm{mmol} / \mathrm{l}$ $(240 \mathrm{mg} / 100 \mathrm{ml})$. Of these 14 , seven had a negative family history, three had a positive history, and in the remaining four the patient could not give sufficient information to make a rating with certainty.

Patients with a family history of coronary heart disease-if they are free of the acknowledged risk factors of cigarette smoking, hypertension, and hyperlipidaemia - can, we believe, in the context of current knowledge, be reassured about their risk of developing clinical coronary heart disease.

\section{References}

1 Ten Kate LP, Boman H, Daiger SP, Moltulsky AG. Family aggregation of coronary heart disease and its relation to known genetic risk factors. Am $\mathcal{F}$ Cardiol 1982; 50: $945-53$.

2 Barrett-Connor E, Khaw KT. Family history of heart attack as an independent predictor of death due to cardiovascular disease. Circulation 1984; 69: 1065-9.

3 Rissanen AM. Family aggregation of coronary heart disease in a high incidence area (North Karelia, Finland). Br Heart f 1979; 42: 294-303.

4 Rissanen AM, Nikkilä EA. Aggregation of coronary risk factors in families of men with fatal and non-fatal coronary heart disease. Br Heart f 1979; 42: 373-80.

5 Epstein FH. Hereditary aspects of coronary heart disease. Am Heart $\mathcal{F}$ 1964; 67: 445-56.

6 Epstein FH. Risk factors in coronary heart disease: environmental and hereditary influences. Isr $\mathcal{F ~ M e d ~ S c i}$ 1967; 3: 594-607.

7 McKusick VA. Genetic factors in cardiovascular diseases: 1. The four major types of cardiovascular disease. Mod Concepts Cardiovasc Dis 1959; 28: 535-42.

8 Sholtz RI, Rosenman RH, Brand RJ. The relationship of reported parental history to the incidence of coronary heart disease in the Western Collaborative Group study. Am J Epidemiol 1975; 102: 350-6.

9 Cambien F, Richard JL, Ducimetière P. Etude des antécédents famillaux de cardiopathies ischémiques et d'hypertension artérielle en liason avec la prévelance des facteurs de risque et l'incidence des cardiopathies ischémiques. L'étude prospective parisienne. Rev Epidemiol Sante Publique 1980; 28: 21-37.

10 Snowden CB, McNamara PM, Garrison RJ, Feinleib $M$, Kannel WB, Epstein FH. Predicting coronary disease in siblings - a multivariate assessment. The Framingham heart study. Am $\mathcal{F}$ Epidemiol 1982; 115: 217-22.

11 Salonen JT, Puska P. Relation of serum cholesterol and triglycerides to risk of acute myocardial infarction cerebral stroke and death in Eastern Finnish male population. Int $\mathcal{F}$ Epidemiol 1983; 12: 26-31.

12 Mulcahy $\mathbf{R}$, Conroy $\mathbf{R}$. How common are risk factors among young patients suffering heart attacks? [Letter] Br Med F 1984; 289: 1228. 